\title{
Impact of a remote lab on teaching practices and student
}

\section{learning}

Clara Viegas, Ana Pavani ${ }^{b}$, Natércia Lima ${ }^{a}$, Arcelina Marquesa ${ }^{a}$ Isabel Pozzoc,

Elsa Dobbolettad ${ }^{d}$, Vanessa Atencia ${ }^{b}$, Daniel Barreto $^{b}$, Felipe Calliari $^{\mathrm{b}}$, André Fidalgo $^{\mathrm{a}}$, Delberis Lima ${ }^{b}$, Guilherme Temporãob ${ }^{b}$ Gustavo Alves ${ }^{a}$

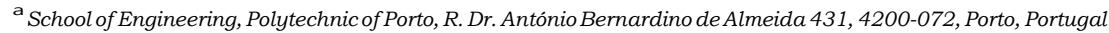

${ }^{\mathrm{b}}$ Pontifícia Universidade Católica do Rio de Janeiro, R. Marquês de São Vicente 225, Rio de Janeiro, Brazil

${ }^{c}$ Rosario Institute for Research in Educational Sciences, Ocampo y Esmeralda, Rosario, Santa Fe, Argentina

${ }^{\mathrm{d}}$ Rosario Regional School, National Technological University, Zeballos 1341, S2000, Rosario, Santa Fe, Argentina
}

Keywords:

Improving classroom

teaching Interactive

learning environments

Pedagogical issues

Teaching/learning

strategies Virtual reality

\section{A B S T R A C T}

Remote Laboratories have become part of current teaching and learning, particularly in en- gineering. Their potential to aid students beyond their hands-on lab classes has been a matter of discussion in literature. Teachers and researchers are aware that the thorough analysis of both strengths and shortcomings of remote labs in didactical implementations may not only lead to the improvement of these resources but also of the pedagogical implications in engineering classes. The present study was carried out in a Higher Education Institution in Brazil in two different courses during three consecutive semesters where a remote lab (VISIR) addressing electric and electronic topics was implemented, yielding 471 students' academic results and opinions. These students' results (while using VISIR) cross-analysed with the course characteristics, reveal some factors teachers may tackle to foster student learning and motivation. The conclusions point to the need for VISIR interface modernization and showed it is more useful in basic courses than in more advanced ones, when dealing with classic lab experiments. Results also show that teachers' involvement plus their ability to brief students on VISIR's usefulness have a significant influence not only on students' performance but also on their perception of learning and satisfaction with the tool. In the analysed cases, the students with more learning needs seemed to be the ones who could benefit more from VISIR. 
In engineering education, the laboratory plays an important role as it is where students can dive into the reality of the concepts and learn to tackle with nature interactions. Apart from knowing and understanding results, engineers need to feel their interaction with real phenomena. For the last 50 years, this has been achieved not only with traditional labs but also with increasing changes driven mainly by the combination of technological development and economic scenarios. Remote labs are a technological response to bring education to an increasing number of communities, with the same level of reality perception as in a traditional (hands-on) lab. Remote labs provide real world measurements whenever a user interacts remotely and instantaneously with the lab system. In the last decade, remote laboratories arose with two major combined objectives: the first was to provide a higher number of students with the opportunity to learn by experimenting through the use of remote resources; the second was to allow institutions to control their budgets since remote labs can reduce the cost of classrooms and labs. A fringe benefit they bring is to allow institutions to easily share remote labs. For countries in deep economic difficulties, this approach is definitely attractive.

\subsection{Remotelaboratories ineducation}

In the early use of remote laboratories, the major concern was effectively providing students with experimental work in their learning process, but it quickly shifted to "what type of competences and skills do they really develop?" (Gomes \& Bogosyan, 2009). Technologies, like virtual or simulation labs, certainly do not develop the same type of skills when compared with hands-on based labs, or even remote labs. While simulation can be used anywhere/anytime, it obeys a mathematical model. However, this does not mean their usage is mutually exclusive. In this vein, several authors support the idea that these technologies can be used in a complementary approach while identifying the different contributions each can bring about to the student learning process (Alves, Viegas, Lima, \& Gustavsson, 2016; Brinson, 2015; Corter, Esche, Chassapis, Ma, \& Nickerson, 2011), and try to identify the different contributions attained in the student learning process, which is not a simple task.

Even though the learning outcome achievements with simulations and remote labs can be considered similar or even higher to the ones students can develop from hands-on labs (Brinson, 2015; Corter et al., 2011), remote labs certainly have different characteristics and may induce different forms of working, allowing students to complement or consolidate their competences. In fact, a "blended" or "hybrid" approach to laboratory learning - a combination of hands-on labs, simulations and remote labs procedures 
- seems to be the most effective, taking advantage on the benefits of the three: knowledge and conceptual understanding outcomes from simu- lations and remote labs and technical skills acquisition from hands-on labs. Besides, the sequence in the laboratory procedure (si- mulation or/and remote labs before hands-on labs or the other way around) seems to make little difference in students' learning outcomes (Brinson, 2015). Remote labs and simulation allow students to access the resources several times as well as a greater amount of time to complete a specific lab task - students can work on their own pace, repeating and adjusting, fostering a deeper learning. Another characteristic, as literature confirms, is that the use of remote labs might potentiate individual work rather than a collaborative one (Herrera, Alves, Fuller \& Aldunate, 2006, pp. 321-325; Gustavsson et al., 2009) thus not contributing to the development of social and scientific communication skills. In fact, it seems more usual that students perform remote lab tasks on their own, opposing to the hands-on labs where students tend to work in groups due to equipment and time constraints. Nevertheless, if students have the opportunity and time to discuss their ideas and communicate with others, it may potentiate collaborative work. Because learning is a complex social process in the sense it intertwines environment, personal trends and learning materials and tools (Corter et al., 2011), this collaboration should be fomented (Felder \& Silverman, 1988). In the field of Electrical and Electronic Engineering, many authors have been developing studies addressing student learning outcomes with simultaneous use of different types of laboratories and resources (Bochicchio \& Longo, 2009; Claesson \& Hakansson, 2012; Feisel \& Rosa, 2005; Fidalgo et al., 2014; Marques et al., 2014).

The use of remote labs also fosters students' lab usage (and study) outside the campus, potentially broaden their skills devel- opment and mitigate their fears in the hands-on lab (Alves, Viegas, et al., 2016). As Heradio et al. (2016) sustain in their work, remote labs can also improve distance-learning potentials, improve accessibility to handicapped people and increase safety in the laboratory. Plus, these resources may offer students the possibility, in some cases, of observing otherwise unobservable phenomena, less set up time, faster results, and minimization of distractions (Brinson, 2015). Furthermore, remote labs can be shared and pooled across the web or between institutions and also provide experimental work to those educational institutions where no real labs exist.

\subsection{VISIR remote laboratory and VISIR + Project}

One of the most successfully used remote laboratories for Engineering Education is VISIR (Virtual Instrument Systems in Reality). Developed by Blekinge Institute of Technology (BTH) in Sweden, it was distinguished in 2015 as the best remote lab by the Global Online Laboratory Consortium (GOLC) Executive Committee ([IAOE] Winners of the GOLC Online Laboratory Award, 2015). VISIR is an open remote lab 
dedicated to experiments in electrical and electronic circuits. It allows teachers and students to remotely practice real-world experiments, with test and measurement equipment, usually found in a traditional electronics lab. In the computer screen, the user interacts with the equipment front panels and breadboard and all the defined electrical connections are then implemented in the relay switching matrix where the provided components are installed. Across Europe, there are more than 10 Higher Education Institutions (HEI) with VISIR remote labs installed. India, Morocco and Latin America (Brazil and Argentina) have also recently installed new VISIR systems, the latter supported by the VISIR + Project (Alves et al., 2016). Hence, the idea behind the VISIR + project was to physically spread this remote lab resource to $\mathrm{HEI}$ in Brazil and Argentina, so they could act as catalists in adopting this solution in their courses as well as in courses from other associated institutions. The major goal of this project, apart from spreading the use of remote laboratories, was helping to define, develop and evaluate a set of educational modules related to electrical and electronic circuit theory and practice, comprising hands-on, simulation and remote labs (VISIR), together with calculus. One of the VISIR + project goals was to recommend an inquiry-based teaching approach where these resources should simulta- neously be used to scaffold students learning. As acknowledged in previous studies (Marques et al., 2014), remote labs should not substitute hands-on labs but rather be used to complement students' study, enlarging their experimental expertise, capacity of dealing with different interfaces and enhancing understanding on the special features of each resource. The ultimate aim was to develop didactic approaches using VISIR which teachers and students would find useful.

The present study shows the results obtained by the implementation of this methodology in one of the Brazilian partners of the VISIR + Project, Pontifícia Universidade Católica do Rio de Janeiro (PUC-Rio) during three consecutive semesters, which contributed to enlarge the VISIR community knowledge. This work has enriched the understanding of the outcomes that different didactical ap-proaches may bring on students in terms of academic performance and satisfaction.

\section{Contextualization}

PUC-Rio is a private non-profit university in Rio de Janeiro, Brazil. It has a Centre for Science and Technology (CTC) that offers undergraduate and graduate Science, Technology, Engineering and Mathematics (STEM) courses/programs. The Department of Electrical Engineering is responsible for two undergraduate curricula - Control \& Automation Engineering and Electrical Engineering, and has joint responsibility, along with the Department of Informatics, for the Computer Engineering curriculum. In 
addition, it offers courses on Electricity to other engineering curricula. This is an important characteristic of the department because it yields a set of students with different interests who take courses on electricity.

\subsection{ICT supported learning at PUC-Rio}

The use of Information and Communication Technology (ICT) tools to support Engineering Education has been going on at PUC- Rio for over two decades. This long lasting and intense activity can be viewed from three different points of view. They are:

\subsubsection{The Maxwell System}

The Maxwell System (https://www.maxwell.vrac.puc-rio.br/) is an integrated platform that hosts an IR Institutional Repository (Lynch, 2003) and an LMS - Learning Management System (Wright, Lopes, Montgomerie, Reju, \& Schmoller, 2014). The IR functions manage all digital contents that range from scholarly publications such as journals, articles, Electronic Theses and Dissertations (ETD), Senior Projects, Monographs, to many types of courseware, such as hypermedia learning objects, videos, simulators and interactive books. The IR characteristics allow each item to be described and uniquely identified; each has only one instance with the same content and digital format. Their use on courses is accomplished by pointing to them on the system, so they are not restricted to a course folder and can be shared and reused; maintenance is easy too. Most courseware is in Open Access and can be reached at the OER - Open Educational Resources link. The IR features were of paramount importance in the deployment and implementation of VISIR@PUC-Rio as it will be addressed in subsection 2.2.

The LMS "personality" of the System offers the traditional LMS functions such as discussion forums, chats, bulletin boards, access to grades, mailing lists, etc. It is compliant with PUC-Rio administrative systems. In order to manage students and instructors, and their relations with contents and activities, there are different spaces as in traditional brick and mortar universities. Before VISIR came to PUC-Rio there were two learning spaces: (1) Classroom (Sala de Aula) where ICT supports traditional face-to-face courses; and (2) Virtual Room (Sala Virtual) where distance learning courses (e-learning) and blended learning (b-learning) courses are hosted. E-learning courses are used in extension continued education. B-learning has been used in undergraduate and graduate engineering courses since the first semester of 2014. In 2017, on-line selfchecking tests and assignment lists were implemented and applied to one b-learning and one traditional course. When VISIR arrived, a new space was necessary, so the Remote Lab (Lab Remoto) space was implemented.

The main objective of this architecture is to emulate the traditional situation where students and faculty can go to different learning spaces, the library, the bulletin board, etc. with no necessity of leaving 
the System.

\subsubsection{Integration with SciLab}

Simulators have been developed and made available in Open Access. The objective of this collection is to offer students an important tool in Engineering Education. Their implementation is based on SciLab® (www.scilab.org/). The objects containing the simulators are hypermedia files with boxes where the user can choose functions or write values that are submitted to SciLab ${ }^{\circledR}$ for processing. This happens on the Maxwell System and the results that SciLab ${ }^{\circledR}$ returns are displayed on the System as well. In order to implement this model, SciLab ${ }^{\circledR}$ had to be integrated into the System. This happened in 2015 when the series Simulations in Electrical Engineering (Simulações em Engenharia Elétrica) was launched. It was the first integration with an external product, but quite different from the one to integrate VISIR.

\subsection{3.}

\subsubsection{Integration with VISIR}

VISIR is a remote lab that is a real resource with a remote access, according to the classification presented by Heradio et al. (2016). This means that VISIR has hardware components besides its software parts.

Though it was quite different from the integration with SciLab ${ }^{\circ}$ it had the same objective - to be seamlessly accessed from the System; it was also considered an additional resource to be offered to students and faculty. It is reached from the Remote Lab learning space when the student enters his class according to the schedule. More details follow.

\subsection{VISIR@PUC-rio}

VISIR@PUC-Rio is a resource that must be examined from two different perspectives: (1) its integration with the Maxwell System; and (2) its use as an ICT supported learning resource.

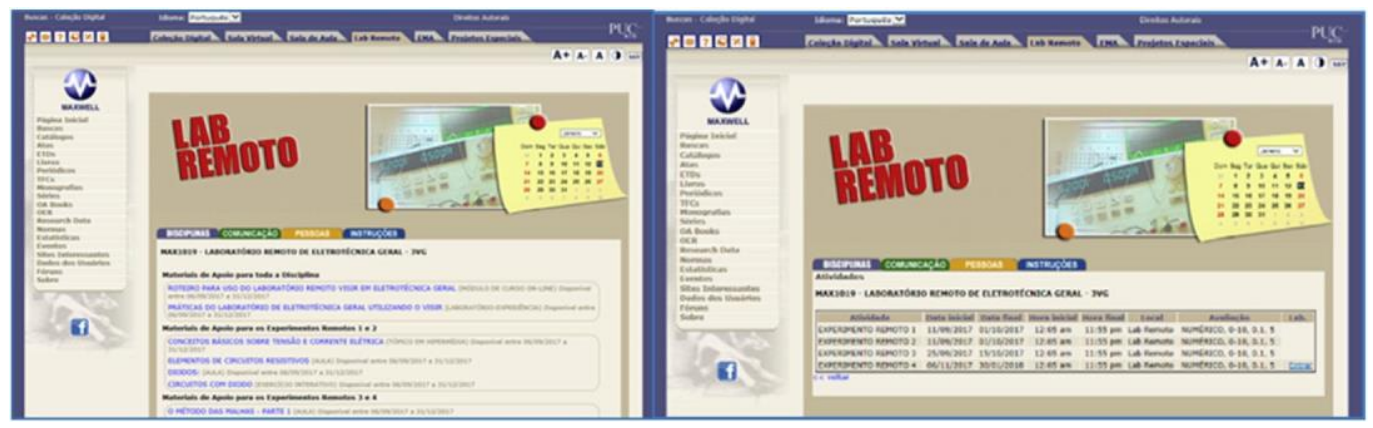

Fig. 1. Organization of the courseware (items are separated according to the topics they address) and access to experiments in the Lab Remoto learning space. 


\subsubsection{Integration with the Maxwell System}

The integration with the Maxwell System was accomplished in three different ways. The first was technical/technological, the second was administrative and the third academic. The full technical/technological integration used features of both the LMS and the IR sides of the System. Pavani, Barbosa, Calliari, Lima, and Cardoso (2017) addressed this topic and also presented the details on the management of the technical documentation that is required by VISIR in order to operate.

The administrative integration focused on transferring administrative functions from VISIR to those of the Maxwell System. Access control, scheduling and logs that were available on the System substituted for the ones on VISIR; the access control was performed by class and experiment, the second based on the experiment schedule, and log level was student, date, time and ex- periment access.

The academic integration meant it had to become one additional resource used to fulfil the needs of the courses syllabi. To accomplish this, syllabi were examined and the VISIR potential use was analysed. VISIR integration in different courses is discussed in subsection 2.4. Since ICT tools have been used for many years at PUC-Rio, many courseware items were already available. In order to fully support VISIR as a remote tool, it was decided that additional courseware should be developed. The learning spaces on the Maxwell System allow courseware, scheduling of activities, discussion forums, bulletin boards, etc. to be offered to students and faculty. The learning space created to accommodate VISIR granted access to the "real" equipment and provided many subspaces.

The first is Materials/Courseware (Materiais), where courseware is organized and presented to users. Fig. 1 (left side) shows Materiais in one of the classes of General Electricity in the second semester of 2017. The second subspace is Activities (Atividades), where students can access experiments when they are available according to the schedule. Fig. 1 (right side) shows Atividades in one of the classes of General Electricity in the second semester of 2017. When an experiment is available, the last column of the table contains a link called Enter (Entrar); it allows the student to access VISIR for the given experiment. Technical details on how this is done can be found in Pavani et al. (2017).

\subsubsection{VISIR as an ICT supported learning resource}

Before VISIR became one of the resources available at PUC-Rio, courseware of various natures had constantly been developed. This courseware is of various natures - hypermedia, animations, videos, simulators, etc. and they are grouped in series. 
Table 1 shows courseware before VISIR and after VISIR. The former offered items that were used with VISIR since they addressed Electric and Electronic Circuits topics. The ones developed to support VISIR meant to complement some topics.

\subsection{Teachers mobilization}

During the implementation of VISIR as a learning resource, eight faculty members from different areas got involved. They par- ticipated in different ways: (1) development of courseware; (2) implementation of experiments; (3) deploying VISIR; and (4) su-pervising the teaching assistants $\left(T_{A}\right)$ and interns who teach the lab classes. One among the eight taught extracurricular activities

Table 1

Maxwell System courseware offer of remotely accessed materials in Electric and Electronic Circuits topics.

\begin{tabular}{|c|c|c|c|c|}
\hline \multirow[t]{2}{*}{ Series } & \multicolumn{2}{|c|}{ Number of items before VISIR } & \multicolumn{2}{|c|}{ Additional number of items after VISIR } \\
\hline & not related to & related to & not related to circuits and/or & related to circuits and/or \\
\hline Learning Objects in EE & 28 & 13 & +2 & +3 \\
\hline Circuits in Video & 0 & 35 & 0 & 0 \\
\hline Simulators & 5 & 2 & +9 & +11 \\
\hline VISIR & 0 & 0 & 0 & +26 \\
\hline $\begin{array}{l}\text { Complementary Topics in } \\
\text { Final series available }\end{array}$ & $\begin{array}{l}0 \\
33\end{array}$ & $\begin{array}{l}0 \\
50\end{array}$ & $\begin{array}{l}+6 \\
50\end{array}$ & $\begin{array}{l}+1 \\
91\end{array}$ \\
\hline
\end{tabular}


The VISIR + project included an initial phase where the recommended didactic methodology for incorporating VISIR was proposed to the partners/teachers (Alves et al., 2016). This idea was presented in the several training actions all teachers had access to in each institution, including PUC-Rio (Viegas et al., 2017).

\subsection{Courses characterization}

Labs of the Electrical Engineering Department are open from Monday to Friday from 7 a.m. to 7 p.m., with the permanent support of technicians to help students (this availability is independent from lab classes). Even so, the use of the VISIR remote lab was the natural step to enrich PUC-Rio System, allowing students to practice at their own pace, from any place and time, as long as they have an internet connection. This study describes the VISIR implementations in two courses: Electric Circuits (EC) (2016: 2nd semester) and General Electricity (GE) (2017: 1st and 2nd semesters).

EC is a mandatory course in the 5th semester curricula of Computer Engineering, Control \& Automation Engineering and Electrical Engineering (EE majors). The course has about 30 students per semester, all in curricula based on electricity. It is a course characterized by students' frequent failures and dropouts and it represents their first contact with the Electronics Lab.

GE is a mandatory course for all engineering students that do not take Electric and Electronic Circuits EE majors. This means

students in Civil, Chemical, Environmental, Industrial, Mechanical, Petroleum and Material and Nanotechnology Engineering must take this course. Depending on their major degree, students can attend it in their 4th, 5th or even 6th semester. It is a course with a large number of students (about 200 students per semester) which means lab classes are usually spread all over the week.

Both courses are actually split in two independent components, one theoretical (EC and GE) and the other laboratorial (ECL and GEL). Students must pass both to progress in their curricula. Table 2 summarizes the main characteristics of both courses, which are taught every semester including recitation (R) and LAB classes. Traditionally, in ECL, every semester, students have to perform 10 experiments in 4 different steps: (1) study and write an outline of the activity, including the expected results; (2) simulate using CircuitLab ; (3) perform the experiment on the workbench; and (4) write a report, which includes comparing the results obtained with each resource. Usually in GEL, the experiments were performed in 3 steps: (1) study the theoretical concepts addressed in the activity; (2) perform the experiment on the workbench; and (3) write and deliver a simple report. 


\section{Methodology}

This study aims to better understand VISIR's potentiality for helping students in their study. It addresses the first large didactic implementations of the VISIR + Project in ECL and GEL courses at PUC-Rio. Different approaches were made based on the courses' characteristics and their roles in different curricula, by focusing on each didactic implementation, on teacher involvement and perceptions, on student involvement, their academic results and satisfaction. The evolution from one semester to the next was also considered. The research question is: "Which factors should teachers tackle to foster student learning and motivation when implementing VISIR in their didactic approach?"

\subsection{Research methodology}

This analysis relies on a Case Study research methodology and combines quantitative and qualitative data (Cohen, Manion, \& Morrison, 2007). The dimensions of analysis and categories are shown in Table 3. Under the scope of the VISIR + project, a set of tools for collecting data were internally developed and validated by the research team involved in the project: teachers pre and post implementation forms; educational modules, teachers' informal contacts and a student questionnaire - SQ (Alves et al., 2016; Pozzo, Borgobello, \& Pierella, 2018). Also, the Maxwell System records which re- sources students accessed through the platform (as long as they were logged in) and also how many times (and when) they accessed them. These tools facilitated the collection of relevant quantitative and qualitative data, namely:

Table 2

EC/ECL and GE/GEL course details (before VISIR).

\begin{tabular}{|c|c|c|c|c|c|c|c|}
\hline \multirow[t]{2}{*}{ Course } & \multirow{2}{*}{$\begin{array}{l}\text { Curricular } \\
\text { Semester }\end{array}$} & \multirow{2}{*}{$\begin{array}{l}\text { Teaching } \\
\text { Method }\end{array}$} & \multirow[t]{2}{*}{ Level of Expertise } & \multirow[t]{2}{*}{ Syllabus Topics } & \multicolumn{2}{|c|}{ Hours/Week } & \multirow{2}{*}{$\begin{array}{l}\text { Number of } \\
\text { Experiments }\end{array}$} \\
\hline & & & & & $\mathrm{R}$ & $\mathrm{LAB}$ & \\
\hline $\mathrm{EC} / \mathrm{ECL}$ & $5^{\text {th }}$ & $\begin{array}{l}\text { Blended } \\
\text { learning }\end{array}$ & Scientific $^{\mathrm{a}}$ & $\begin{array}{l}\text { Basic circuit theory, nonlinear components and } \\
\text { integrated circuits }\end{array}$ & $4+2^{c}$ & 2 & 10 \\
\hline GE/GEL & $4^{\text {th }} / 5$ th $/ 6$ th & $\begin{array}{l}\text { Classroom } \\
\text { lessons }\end{array}$ & Complementary ${ }^{\mathrm{b}}$ & $\begin{array}{l}\text { Analysis of electrical circuits, energy conversion, } \\
\text { magnetic circuits; transformers, principles of } \\
\text { electromechanics and low voltage installations }\end{array}$ & 2 & 1 & 8 \\
\hline
\end{tabular}

\footnotetext{
${ }^{\text {a }}$ EE majors.

b Other majors.

c $4 \mathrm{~h}$ classroom lectures $+2 \mathrm{~h}$ computer mediated.
} 
Dimensions of analysis.

\begin{tabular}{|c|c|c|}
\hline Dimensions & Categories & Factors \\
\hline \multirow[t]{8}{*}{ Didactic } & VISIR's & Course implementation edition \\
\hline & & Additional used resources (simulator, hands-on, calculus) \\
\hline & & Number of tasks using VISIR \\
\hline & & VISIR tasks weight on grade \\
\hline & & Implementation objectives and VISIR's introduction \\
\hline & Teacher involvement & Number of teachers involved \\
\hline & & Teachers' accesses in VISIR \\
\hline & & Teachers' perception \\
\hline \multirow[t]{7}{*}{ Student Results } & Academic & Students' background ( $C R^{a}$, previously addressed topics) \\
\hline & & Students' grades (VISIR tasks, other tasks, lab, exam) \\
\hline & & Students' number of items accessed: remote experiments/reference \\
\hline & Student perception & Learning with VISIR \\
\hline & & Satisfaction with VISIR \\
\hline & & Satisfaction with VISIR support \\
\hline & & External factors \\
\hline
\end{tabular}

a $C R$, student performance coefficient, represents the weighted average grade on previous courses (1-10 scale).

- major degree/course information (institution, curricular semester, type of course, number of teachers involved, number of stu- dents);

- didactic implementation design and results (subject background, VISIR's implementation, number of tasks, teaching methodology, VISIR tasks weight in global grade, number of students and teachers logs on VISIR);

- teacher and student perception of the didactic implementation using VISIR;

- student academic results (grades - VISIR tasks, lab and final, dropouts).

- student usage of internet resources on the Maxwell system (number of resources accessed and number of accesses)

At the end of the course implementation, the head teachers had to fill up a teachers' satisfaction form to evaluate VISIR remote lab, collecting their view about the didactical experience and the main advantages/disadvantages of this resource. The student satisfaction questionnaire (SQ) was delivered in Portuguese, on paper, at the end of the semester, before the end of classes. For the sake of correlating students' answers with their academic results, students were asked to identify themselves through their academic ID numbers which was codified. This was explained to students in order to guarantee their privacy and to acknowledge that their answers would not have any implication on their grades. This questionnaire had 20 closed questions in a 4-level Likert agreement scale (1-minimum; 4-maximum) and 2 open questions. According to Cohen et al. (2007), in order to be able to test its validity and its reliability, several questions were designed to address each specific issue according to VISIR + Project research purpose. The questionnaire followed the validation method described by Collingridge (2014). The first step was to establish face 
validity. Ac-cording to it, the survey was reviewed by two different parties. The first was a group of researchers familiar with the topic - members of the research team, capable of evaluating if the questions captured the topic. The second review came from external colleagues who were experts on questionnaire construction, ensuring that it did not contain formal errors. The second step was a pilot test with a group of the intended participants and minor adjustments were made. In the third step, the questionnaire was set up with target population and data was collected. In step four, Principal Components Analysis was carried out to identify underlying factors measured by the survey questions and combining those that load onto the same factors in the final analysis of data. This step validated the number of factor-themes measured by the survey and aligned with this research. For this study 3 factors were identified: F1 - Perceived learnings (with 6 questions addressing students' perceived comprehension of the subject and their lab confidence skills); F2 - Satisfaction with VISIR (with 8 questions addressing VISIR usage and the perceived added values); F3 Satisfaction with support (with 4 questions addressing the perceived assistance towards the system, manuals). Finally, internal consistency of questions

Table 4

Student Questionnaire (SQ) Internal Consistency Analysis (Cronbach alpha).

Table 4

Student Questionnaire (SQ) Internal Consistency Analysis (Cronbach alpha).

\begin{tabular}{llllll}
\hline Course & N & N SQ & F1 & F2 & \\
\hline ECL 16-2nd semester & 29 & 17 & 0.568 & 0.643 \\
GEL 17-1st semester & 260 & 254 & 0.646 & 0.273 \\
GEL 17-2nd semester & 182 & 132 & 0.643 & 0.344 \\
\end{tabular}

loading onto the same factor was checked through Cronbach's alpha to determine whether the responses were consistent, considering it acceptable if equal or higher than 0.6 (Table 4).

This analysis shows internal consistency in F1 and F2 (even though at a low level) but not in F3 (Cronbach alpha $<0.5$ ). For this reason, F3 will only be qualitatively analysed as well as one extra factor F4 - External factors, which was only addressed by one closed question (related to the internet connection).

The open questions were qualitatively analysed, following the procedure of the Grounded Theory (Glaser \& Strauss, 1967), identifying categories given the students' expressed opinions, in spite of the minor variants with which they were formulated or the internal aspects to which they refer to. These categories were proposed by the members of the research team in charge of the data collection work and then checked by external colleagues familiar with the topic. 


\subsection{Case studies characterization}

In this study there will be two case studies: Case A - Electric Circuits Lab (in an EE major degree) and Case B General Electricity Lab (in non-EE major degrees). In both VISIR was implemented in two semesters. However, the first one in the first semester (A1) was a piloting stance run, before the data collection within the VISIR + project was established and thus will not be part of the analysis. During the pilot run PUC-Rio equipment had not arrived so CUAS (Carinthia University of Applied Science) equipment was used.

For this pilot one experiment was selected (the last one from the syllabus) and an extra step was added, that is using VISIR between simulation and hands-on lab practise. Due to the pilot success, in the following semester, VISIR was implemented in this course again. The 3 last experiments of the syllabus were also chosen to have VISIR as an additional step. So, in these 3 experiments students had a lab sequence of 5 steps and in the other 7 experiments (without VISIR) they had the usual 4-step procedure. In Case A2, students were graded through the outlines they presented (30\%), their performance and reports on the experiments (30\%) and a test at the end of the course (40\%). In the hands-on Lab students worked in pairs - while performing VISIR experiments students worked on their own (such as in simulations). As VISIR was used by the students nearly at the end of the semester, when they were already familiar with the lab equipment, teacher introduction to VISIR in class was very brief.

When the GE teachers were introduced to VISIR, they figured it was a good tool to enhance experimentation in the lab component, since it deals with about 200 students per semester, split in 1-h Lab classes. They examined VISIR to decide the experiments that could be performed in compliance with the course syllabus. Case B deals with voltages and currents higher than the ones supported by VISIR, so the decision was to use VISIR for basic concepts of electric circuits. Four new experiments were added to the syllabus (Ohmic Circuit, Non-Ohmic Circuit, Series-Parallel Circuit and Resistive Circuit with Voltage to be determined); meaning an increase of $50 \%$ in the lab experiments ( 8 experiments using hands-on lab and 4 using VISIR). The first 2 experiments were performed in the same class (the first of the semester, where VISIR was introduced) and were combined to yield a single grade. In that class, teachers explained and trained their students in the use of VISIR, particularly in relating breadboards, instruments, sources, etc., that are available at the lab. Since VISIR is a remote lab, students did not have to go to the lab classes to perform the experiments and they were given about 20 days to accomplish each task. Although this course was conducted in a similar way both semesters of 2017 , students final grade was obtained in a slightly different way. In the first semester (Case B1) it was a combination of the average grade obtained in VISIR tasks (20\%) and the average grade obtained in the traditional lab (80\%). In the second semester (Case 
B2), teachers introduced 3 lab tests, to help students study the underlying lab theoretical concepts and the final grade was a combination of the average grade obtained in VISIR tasks (20\%), the average grade obtained in the lab tests (20\%) and the average grade obtained in the traditional lab (60\%). Therefore, for both semesters students performed 4 experiments with VISIR with a contribution to the final grade of $20 \%$.

In both Cases students performed the VISIR experiments on their own in opposition to the traditional Lab, where students worked in pairs. Also, both courses had faculty members $(T)$ who lectured recitation classes and helped plan the experiments and on the other hand teaching assistants $\left(T_{A}\right)$, who delivered the lab classes. In order to achieve a good use of VISIR, the technical staff and faculty members who had installed and understood the equipment trained the $\mathrm{T}_{\mathrm{A}}$.

Teachers introduced VISIR to students and implemented it in their courses (along with other resources), using it according to their purposes. Table 5 summarizes these results, including the number of teachers/students involved, resources used, goal for using VISIR and how it was introduced to students as well as some details about the usage in the semester and its contribution to the final grade.

Table 5

Case studies characterization.

\begin{tabular}{|c|c|c|c|c|c|}
\hline \multirow[t]{2}{*}{ Description } & & \multicolumn{2}{|c|}{ CASE A: Electric Circuits Lab } & \multicolumn{2}{|c|}{ CASE B: General Electricity Lab } \\
\hline & Implementation & A1: 2016-1st semester & A2: $2016-2 n d$ & B 1 : 2017-1st & B2: 2017-2nd \\
\hline \multirow[t]{8}{*}{ General } & N Head Teachers & 1 & $1+1$ & $2+2$ & $2+2$ \\
\hline & $+\mathrm{N}$ Teaching & & & & \\
\hline & Resources & \multicolumn{2}{|c|}{ VISIR, Simulation, Calculus, Hands-on Lab, } & \multicolumn{2}{|c|}{ VISIR, Calculus, Hands-on Lab, Hypermedia } \\
\hline & & \multicolumn{2}{|l|}{ Hypermedia } & \multicolumn{2}{|c|}{ Learning objects, Videos and Interactive } \\
\hline & & \multicolumn{2}{|c|}{ Learning objects, Videos and Interactive } & \multicolumn{2}{|l|}{ Books } \\
\hline & & \multicolumn{4}{|l|}{ Books } \\
\hline & Experimental steps & \multicolumn{2}{|c|}{ Simulator and VISIR and Hands-on lab } & \multicolumn{2}{|c|}{ VISIR or Hands-on } \\
\hline & lab N All Lab tasks & \multicolumn{2}{|l|}{10 experiments } & \multicolumn{2}{|c|}{12 experiments } \\
\hline
\end{tabular}


Table 5 (continued)

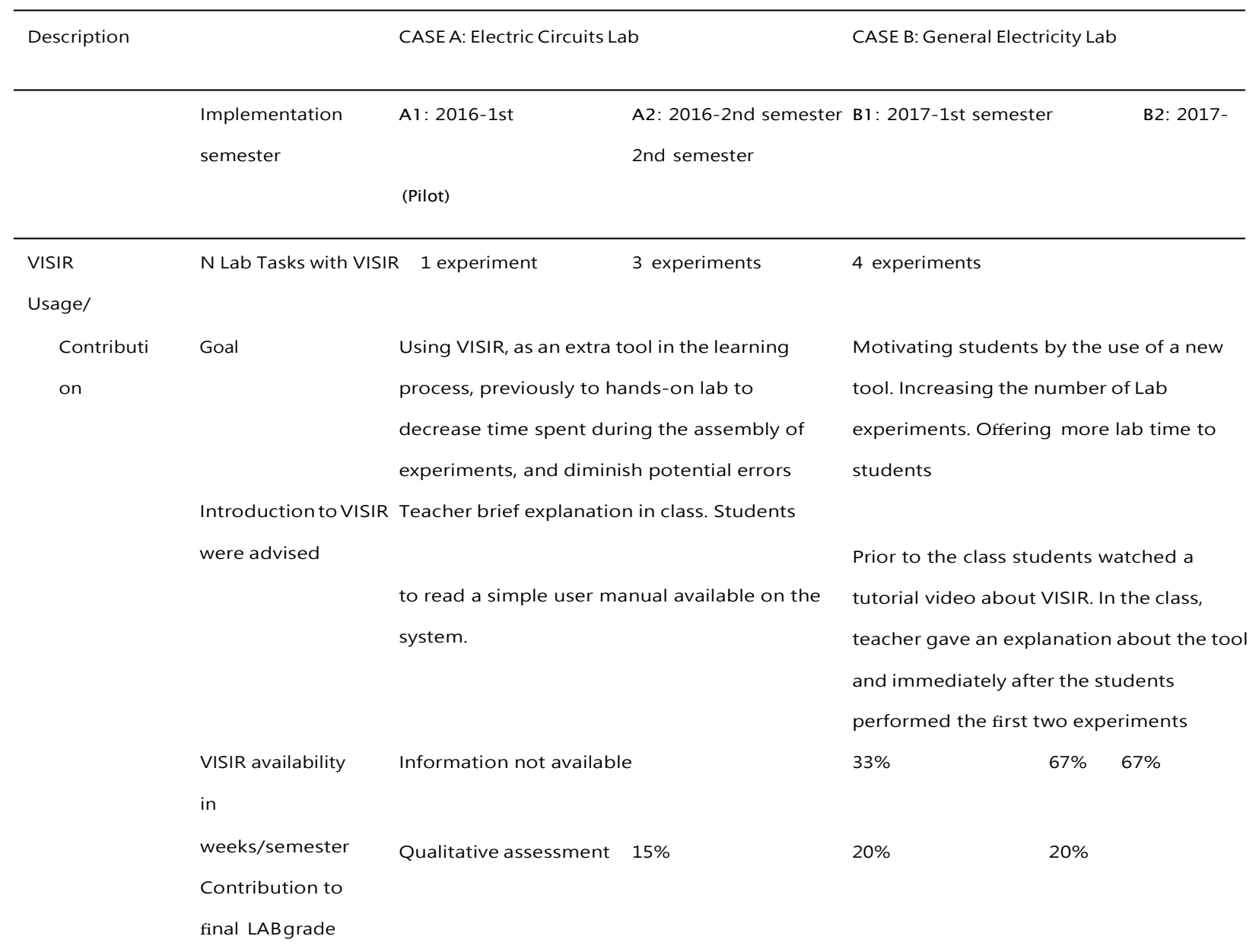




\section{Results}

\subsection{Didactical implementation results}

The first implementation occurred as a pilot in the 1st semester of 2016 (Case A1) and the main idea of applying VISIR in Electric Circuits was to introduce a new step between simulation and hands-on lab, so students could get more familiarized with electric components and equipment and become more confident when using the hands-on lab. In the end the teacher asked students to grade VISIR's usage through their level of agreement in three statements. The result was very encouraging: accordingly, students found VISIR user-friendly and intuitive; and their usage had a positive impact on them. This pilot test was also important to faculty because it showed the importance of planning the experiments to be performed along the semester - VISIR requires set up activities that may be time consuming.

According to the previous results, in the following semester (Case A2), 3 out of the 10 experiments (the last three) had an additional step (use of VISIR) in the usual procedure, becoming lab sequences with 5 steps. As all experiments had an equal con-tribution to the lab course final grade, students complained about the extra load of work with these 3 experiments, without any measurable gain. In some students' opinion "VISIR did not add any functionality that the hands-on lab didn't have". Also, student introduction to VISIR was not fully prepared/planned. The teacher believed that since VISIR started being used in the second half of the semester and the students were from the EE area, they would naturally adjust to the new tool. This may have also contributed to students not fully appreciating VISIR. Moreover, since students are allowed to go to the traditional lab at any time the lab is open and assemble/experiment as many circuits and components they want and also the technical staff who were always available to support them, VISIR was not perceived as a major asset.

The reality of Case B is rather different. Student core curricula was not on EE area and they took the course because it was mandatory. The great majority of students were not particularly interested in electricity. Due to the distinctive characteristics of this course, being more generalist and addressing some lab resources constraints, the implementation strategy was quite different. Four new experiences were introduced, which were not available/done in the hands-on lab, and students were properly trained to use VISIR. In fact, teachers introduced it, doing some assembling with students, while explaining the resemblance with the traditional lab (breadboard, components, and instruments). The first 2 VISIR 
experiments were performed in the class where VISIR was introduced,

i.e. before students first experiment in the traditional lab; the other two experiments were made over the semester. Thus, students could practise the basic concepts of electric circuits, before going to the handson lab, with no need to attend the university to practise. They could also repeat them as many times as they wished with no need of synchronous activities. The immediate perception

was that VISIR was an advantage as it allowed students to practise in a different and simpler way. The teaching assistants were very enthusiastic with VISIR and this enthusiasm probably spread to the students. VISIR allowed more contents to be added as well as yielded new studying opportunities otherwise unavailable.

As stated in literature (Cunha, Saraiva, Santos, Dinis, \& Lopes, 2014; Marques et al., 2014) teacher mediation is crucial in order to 
Table 6

Teacher VISIR usage characterization.

\begin{tabular}{|c|c|c|c|c|c|}
\hline \multicolumn{2}{|c|}{ Implementation Edition } & \multirow{2}{*}{$\begin{array}{l}\text { Number of VISIR Experiments } \\
3\end{array}$} & \multirow{2}{*}{$\begin{array}{l}\text { Number of Teachers } \\
2\end{array}$} & \multirow{2}{*}{$\begin{array}{l}\text { Number of VISIR logs } \\
21\end{array}$} & \multirow{2}{*}{$\begin{array}{l}\text { VISIR's logs/task } \\
7.0\end{array}$} \\
\hline Case A2 & $2^{\text {nd }}$ & & & & \\
\hline Case B1 & $1^{\text {st }}$ & 4 & 4 & 99 & 24.8 \\
\hline Case B2 & $2^{\text {nd }}$ & 4 & 4 & 83 & 20.8 \\
\hline
\end{tabular}

Table 7

Teacher VISIR usage perception.

Advantages

Case A In my opinion VISIR only enhances lab teaching, being an intermediate step between the reallaboratory and the simulation. Adding to this, there are unique VISIR possibilities, such as hidden components in a black box; it is an excellent didactic tool (Head Teacher). Similarity with real equipment available on hands-on lab (protoboard, function generator, multimeter, oscilloscope) (Teaching assistant).

Case B Freedom for students to access from anywhere and at any time and possibility of previous study and experimentation before the final "round" (Head Teacher).

After working with VISIR students showed more confidence at hands-on lab and were able to establish links between theoretical concepts and the experiments(Teaching assistant).

\section{Disadvantages}

Perhaps the interface is a bit too simple and does not arouse the enthusiasm of young students (Head Teacher).

Limitation of the number of combinations on the same experiment (Teaching assistant).

Limitation/restriction of experiments due to the need for prior assembly, which is time consuming (Head Teacher).

Restriction on the number of measurements devices connected simultaneously (Teaching assistant). 
engage students in productive work. Teacher enthusiasm regarding the usage of a new tool will potentiate student usage. Without teachers' incentive to use it and suitable justification about its utility, students have more difficulty to overcome the initial challenges VISIR might pose to a new user. On the other hand, teachers' own usage of VISIR is fundamental to closely and quickly acknowledge student doubts. In this study, the teachers' reactions to the use of VISIR were quite different in both Cases, even though all teaching assistants $\left(T_{A}\right)$ who performed the lab classes provided VISIR assistance to students. Table 6 shows the number of teachers in each course and the number of logs into the system, including the task preparation phase and the support given along the semester.

The teachers' roles are distinct and well defined in both courses: head teachers are responsible for defining the course, the lab experiments and recitation classes, as the teaching assistants are responsible for lab classes. Both head teachers (from both courses) considered VISIR easy to use, with a somewhat friendly interface and components suitable for their needs. They found the procedures were easy to use and carry out, so they did not feel the need to use VISIR manuals. Case B's head teacher also mentions having noticed two problems in the system: (1) Loss of the mapping of the connection points when resizing the window and (2) Possibility of connecting two wires at the same point, which cannot be done on a "real" breadboard (with the additional problem that sometimes it worked and others it did not). Teaching assistants are responsible for almost every VISIR log since they had the responsibility of accompanying the experimental and students work with VISIR. It is noticeable that B1 and B2 Cases exhibit a greater number of logs per task than in Case A2, even considering that there were less teachers (Table 6).

When asked to point out VISIR's great advantages and disadvantages, all teachers shared a general positive opinion, which is shown in Table 7.

\subsection{Student results}

Ultimately, the goal of any didactical intervention is the improvement of student academic results, as a direct result on their scholar achievements and/or on their satisfaction and motivation. This section addresses both aspects for each Case, characterizing student results in terms of their accomplished work with VISIR and their perception of this usage. This will contribute to a better understanding of what kind of influence VISIR possibly had in student developments and achievements. Firstly, a quantitative 
analysis will be addressed including the results on student involvement, grades and perception. Secondly, a qualitative analysis will be carried out, conducting a content analysis of student opinions stated on the open questions of the questionnaire (SQ).

Students (individually) accessed the experiments several times and the logs indicate that a meaningful number of accesses were out of the office hours. The average characterization of this VISIR usage and other remotely accessed items the Maxwell platform provided (see Table 1 ) is shown in Table 8. The average number of student VISIR logs per task varies between 0 (only 2 students in a population of 471) and 5.3 (1 student from Computer Engineering).

As can be observed in Table 8, students from Case B2 had lower attendance scores on these remote tools in general, and a similar outcome is also present in the remote experiments with VISIR.

Student perception of VISIR usage was obtained essentially from the student questionnaires. The results on the two valid factors of analysis (F1 - Perceived learnings and F2 - Satisfaction with VISIR) showed a significant difference on the central tendency (median) of the questions related to these factors in the lectured courses (Cases A2, B1 and B2), as observed in Fig. 2.

Both F1 and F2 have a considerably lower level of agreement in Case A2 than in Case B (for instance, Case $\mathrm{A} 2$ shows that $62 \%$ of the answers in the questions related to $\mathrm{F} 2$ have a "level 1 " in Likert-scale, in relation to all answers in F2 (in this case); on the other

Table 8

Student average usage of the remotely accessed materials.

\begin{tabular}{|c|c|c|c|c|c|c|}
\hline & \multicolumn{2}{|c|}{ Remote experiments(VISIRlogs) } & \multicolumn{2}{|l|}{ Course contents } & \multicolumn{2}{|l|}{ Reference materials } \\
\hline & $\mathrm{N}$ accessed items & $\mathrm{N}$ accesses/task & $\mathrm{N}$ accessed items & $\mathrm{N}$ accesses & $\mathrm{N}$ accessed items & $N$ \\
\hline Case A2 & 1.80 & 2.6 & 0.96 & 1.68 & 0.20 & 0.24 \\
\hline Case B1 & 2.74 & 2.7 & 1.72 & 3.34 & 0.02 & 0.10 \\
\hline Case B2 & 2.11 & 2.0 & 0.28 & 0.4 & 0.11 & 0.10 \\
\hline
\end{tabular}




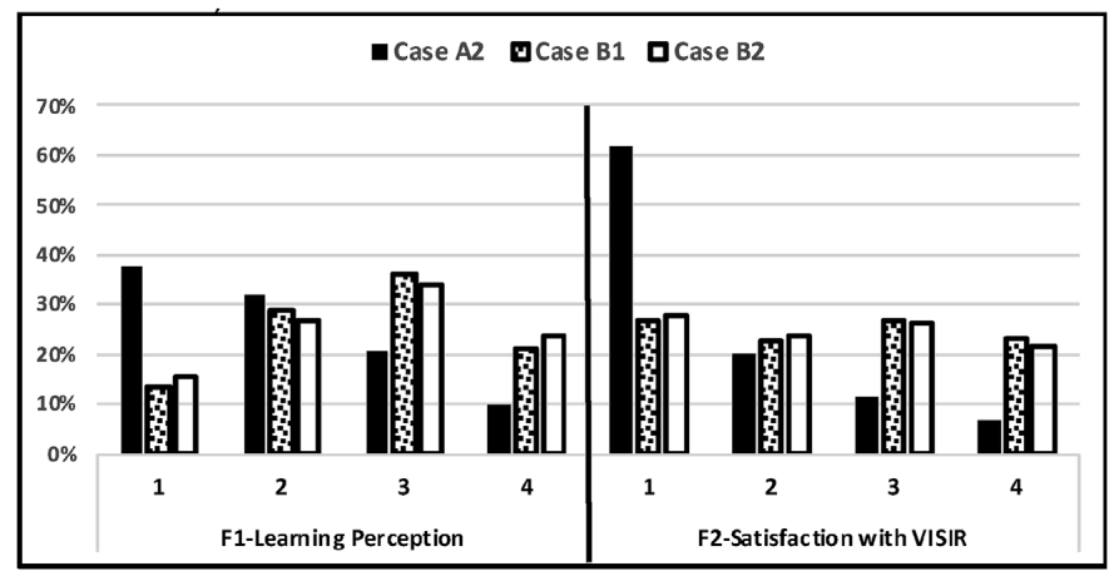

Fig. 2. Factor frequency analysis (in the 4-level Likert scale) for the global student responses in the questions of each factor.

hand, both Cases B1 and B2 show percentages lower than $30 \%$ and distributed through all levels, see Fig. 2). Case B, in both semesters, registers a similar distribution of students' answers, a higher perception of learning with VISIR (F1) and an equivalent distribution of the level of agreement regarding their satisfaction with VISIR (F2). In the second semester (B2) students had lower levels of usage on remote experiences and course contents, not only do they seek a lower number of resources but they also do it fewer times. In A2, students demonstrate lower levels in both factors, contrasting with the previous (pilot) course (A1) when VISIR was used for the first time in one experiment (as registered by those teachers).

Regarding student academic performance, a difference can be observed between the two courses: in general students achieve better grades in Case B (basic course) than in Case A (scientific course). This characterization is visible per component (VISIR, other tasks, lab and exam) and the student performance coefficient (CR, 1-10 scale). Table 9 summarizes this information in average for each course and per major degree.

Table 9 shows that in general students had better grades in "other tasks" than in the ones involving VISIR. This difference is higher in Case A2 and was probably responsible for diminishing their lab grades, so it is natural that the students' opinion somehow reflects an agreement with the tool perception.

However, VISIR grades show significant correlations (Pearson correlations) with lab and exam grades in all courses: in Case A2, $r=0.795(p<0.001)$ and $r=0.442(p=0.027)$, respectively; in Case B1, $r=0.723$ and $r=0.427$ (both $p<0.001$ ); and in Case B2, $r=0.763$ and $r=0.523$ (both $p<0.001$ ). Comparing these correlations with the ones that appear between "other tasks" grades and lab or exam grades, they are similar, although stronger in Case A2 and Case B1 and weaker in Case B2. Since in all cases the 
Table 9

Student academic performance characterization.

\begin{tabular}{|c|c|c|c|c|c|c|c|c|c|c|c|}
\hline & \multirow[t]{2}{*}{ Engineering Major } & \multirow[t]{2}{*}{ NSTD } & \multirow[t]{2}{*}{$\mathrm{N}$ dropouts } & \multirow[t]{2}{*}{$\mathrm{CR}$} & \multicolumn{2}{|c|}{ Student Perception } & \multicolumn{4}{|c|}{ Average Grade (\%) } & \multirow[t]{2}{*}{ Pass (\%) } \\
\hline & & & & & $\mathrm{F} 1$ & $\mathrm{~F} 2$ & VISIR tasks & Other & Lab & Exam & \\
\hline \multirow[t]{3}{*}{ Case A2 } & Computer & 16 & 2 & 7.1 & 2 & 1 & 50.7 & 80.3 & 63.3 & 51.0 & 63 \\
\hline & Control & 5 & 1 & 6.6 & 3 & 1 & 49.8 & 74.6 & 54.4 & 45.0 & 20 \\
\hline & $\begin{array}{l}\text { Electrical } \\
\text { All STD }\end{array}$ & $\begin{array}{l}8 \\
29\end{array}$ & $\begin{array}{l}0 \\
3\end{array}$ & $\begin{array}{l}7.0 \\
7.0\end{array}$ & $\begin{array}{l}2 \\
2\end{array}$ & $\begin{array}{l}1 \\
1\end{array}$ & $\begin{array}{l}62.3 \\
53.9\end{array}$ & $\begin{array}{l}83.4 \\
80.2\end{array}$ & $\begin{array}{l}74.3 \\
64.8\end{array}$ & $\begin{array}{l}52.5 \\
53.5\end{array}$ & $\begin{array}{l}75 \\
59\end{array}$ \\
\hline \multirow[t]{7}{*}{ Case B1 } & Chemical & 31 & 0 & 7.1 & 3 & 2 & 82.1 & 95.6 & 93.1 & 71.9 & 94 \\
\hline & Civil & 60 & 0 & 6.9 & 3 & 3 & 83.2 & 93.8 & 91.7 & 73.2 & 97 \\
\hline & Computer & 1 & 0 & & 2.5 & 2 & 100 & 85.6 & 88.5 & 17.0 & 0 \\
\hline & Environmental & 4 & 0 & 6.7 & 3 & 3 & 78.3 & 97.1 & 93.4 & 63.8 & 100 \\
\hline & Materials \& & 1 & 0 & 6.1 & 4 & 4 & 66.7 & 67.5 & 67.3 & 71.0 & 100 \\
\hline & Mechanical & 44 & 1 & 7.1 & 3 & 3 & 86.4 & 93.5 & 92.3 & 71.1 & 93 \\
\hline & $\begin{array}{l}\text { Industrial } \\
\text { All STD }\end{array}$ & $\begin{array}{l}119 \\
260\end{array}$ & $\begin{array}{l}1 \\
2\end{array}$ & $\begin{array}{l}6.9 \\
7.0\end{array}$ & $\begin{array}{l}3 \\
3\end{array}$ & $\begin{array}{l}2 \\
3\end{array}$ & $\begin{array}{l}83.6 \\
83.7\end{array}$ & $\begin{array}{l}94.3 \\
94.1\end{array}$ & $\begin{array}{l}92.2 \\
92.1\end{array}$ & $\begin{array}{l}71.3 \\
71.4\end{array}$ & $\begin{array}{l}93 \\
94\end{array}$ \\
\hline \multirow[t]{9}{*}{ Case B2 } & Chemical & 27 & 0 & 8.0 & 3 & 2 & 95.0 & 97.7 & 96.9 & 83.8 & 100 \\
\hline & Civil & 35 & 0 & 6.8 & 2 & 2 & 81.5 & 97.0 & 91.1 & 74.3 & 97 \\
\hline & Computer & 1 & 0 & 7.2 & 3.5 & 2.5 & 100 & 99.0 & 93.0 & 88.0 & 100 \\
\hline & Electrical & 2 & 0 & 8.2 & 2 & 1 & 100 & 100 & 100 & 90.0 & 100 \\
\hline & Environmental & 10 & 0 & 7.7 & 3 & 2 & 72.3 & 88.1 & 86.6 & 73.9 & 100 \\
\hline & Materials \& & 1 & 0 & 6.5 & 4 & 3 & 75.0 & 96.0 & 93.0 & 64.0 & 100 \\
\hline & Mechanical & 21 & 0 & 7.0 & 3 & 2 & 92.0 & 94.7 & 93.4 & 75.2 & 100 \\
\hline & Petrol & 2 & 0 & 6.9 & 3.5 & 2.5 & 98.5 & 97.1 & 96.0 & 73.5 & 100 \\
\hline & $\begin{array}{l}\text { Industrial } \\
\text { All STD }\end{array}$ & $\begin{array}{l}83 \\
182\end{array}$ & $\begin{array}{l}1 \\
1\end{array}$ & $\begin{array}{l}7.6 \\
7.2\end{array}$ & $\begin{array}{l}3 \\
3\end{array}$ & $\begin{array}{l}3 \\
2\end{array}$ & $\begin{array}{l}83.2 \\
85.4\end{array}$ & $\begin{array}{l}91.8 \\
94.0\end{array}$ & $\begin{array}{l}89.9 \\
91.6\end{array}$ & $\begin{array}{l}74.4 \\
77.4\end{array}$ & $\begin{array}{l}99 \\
99\end{array}$ \\
\hline
\end{tabular}


Table 10

Student performance correlations with remote tools usage and perception.

\begin{tabular}{|c|c|c|c|c|c|c|c|c|c|}
\hline & & \multicolumn{2}{|l|}{ Student } & \multicolumn{2}{|l|}{ Remote } & \multicolumn{2}{|l|}{ Course contents } & \multicolumn{2}{|c|}{ Reference materials } \\
\hline & & F1 median & $\mathrm{F} 2$ & $\mathrm{~N}$ experiments & N VISIR logs/task & $\mathrm{N}$ items accessed & $\mathrm{N}$ accesses & $\mathrm{N}$ items accessed & $\mathrm{N}$ accesses \\
\hline \multirow[t]{4}{*}{ Case A2 } & $\begin{array}{l}\text { VISIR tasks } \\
\text { grades }\end{array}$ & n.s. & n.s. & & $r=0.560(p=$ & & & & \\
\hline & Lab grades & n.s. & n.s. & n.s. & $r=0.678(p<$ & $\begin{array}{l}r=-0.559 \\
(p=0.004)\end{array}$ & $\begin{array}{l}r=-0.458 \\
(p=0.021)\end{array}$ & n.s. & n.s. \\
\hline & Exam grades & n.s. & n.s. & n.s. & n.s. & $\begin{array}{l}r=-0.559 \\
(p=0.004)\end{array}$ & $\begin{array}{l}r=-0.524 \\
(p=0.007)\end{array}$ & n.s. & n.s. \\
\hline & $C R$ & n.s. & n.s. & n.s. & n.s. & $\begin{array}{l}r=-0.571 \\
(p=0.004)\end{array}$ & $\begin{array}{l}r=-0.564 \\
(p=0.004)\end{array}$ & n.s. & n.s. \\
\hline \multirow[t]{4}{*}{ Case B1 } & $\begin{array}{l}\text { VISIR tasks } \\
\text { grades }\end{array}$ & $\begin{array}{l}r=-0.127 \\
(p=0.042)\end{array}$ & n.s. & & $\begin{array}{l}r=0.339 \\
(p<0.001)\end{array}$ & & & & \\
\hline & Lab grades & $\begin{array}{l}r=-0.162 \\
(p=0.009)\end{array}$ & n.s. & $r=0.339(p<$ & $\begin{array}{l}r=0.207 \\
(p<0.001)\end{array}$ & n.s. & n.s. & $\begin{array}{l}r=-0.272 \\
(p<0.001)\end{array}$ & n.s. \\
\hline & Exam grades & n.s. & n.s. & $r=0.196(p=$ & $r=0.139(p=$ & n.s. & n.s. & n.s. & n.s. \\
\hline & $\mathrm{CR}$ & n.s. & n.s. & $r=0.130(p=$ & n.s. & n.s. & n.s. & $r=-0.158(p=$ & $\begin{array}{l}r=-0.158 \\
(p=0.012)\end{array}$ \\
\hline \multirow[t]{4}{*}{ Case B2 } & $\begin{array}{l}\text { VISIR tasks } \\
\text { grades }\end{array}$ & n.s. & n.s. & & $\begin{array}{l}r=0.348 \\
(p<0.001)\end{array}$ & & & & \\
\hline & Lab grades & n.s. & n.s. & $r=0.321(p<$ & $\begin{array}{l}r=0.344 \\
(p<0.001)\end{array}$ & n.s. & n.s. & n.s. & $\begin{array}{l}r=-0.167 \\
(p=0.025)\end{array}$ \\
\hline & Exam grades & n.s. & n.s. & $r=0.243(p<$ & $\begin{array}{l}r=0.315 \\
(p<0.001)\end{array}$ & n.s. & n.s. & n.s. & \\
\hline & $C R$ & n.s. & & $\mathrm{r}=0.211(\mathrm{p}=$ & $\mathrm{r}=0.175(\mathrm{p}=$ & n.s. & n.s. & n.s. & n.s. \\
\hline
\end{tabular}

Legend: "n.s." means no significant correlation was found. 
"other tasks" had a higher weight in student grades (85\% in Case A2 and 80\% in both Cases B1 and B2), these results add value to the correlations found with the VISIR tasks.

Comparing student grades in the two courses it is evident that in Case B students generally performed better, but this has no relation with the VISIR tasks performance, as similar correlations occur in the other grade components as well. In fact, in Case B students also showed a higher level of satisfaction with it (both in terms of perceived learning and in terms of satisfaction with VISIR).

Analysing and correlating each student data regarding the number of VISIR accesses per task (i.e., individual logs), the perception of learning (F1) and their actual grades, several significant (Pearson) correlations emerge, as observable in Table 10.

As expected, student logs per task are significantly correlated with their grades in "VISIR tasks" and "lab" in all courses. As the analysis becomes more general (with the exam or CR) this correlation naturally disappears or becomes weaker. This supports that in general, the more students accessed VISIR, the better results they achieved, although these results may also naturally be related with the students' hardworking abilities. Even so, the fact that student involvement with VISIR relates to student performance in VISIR as well in all the other components, suggests that this tool can also be supporting their learning.

There were no significant correlations between student grades or number of logs per task with their satisfaction with VISIR (F2). This is also true in relation with "problems with the server" (one specific question of the SQ): no correlation exists between students' answers to this question and the number of their logs on VISIR. These particular results support the idea that their VISIR usage was not directly related with their satisfaction with the system. Also keeping in mind that the students who achieve better grades are the ones who accessed VISIR the most because they are more committed. In terms of student learning perception (F1), the negative correlations with Case B1 student grades (Table 10), even though difficult to interpret at first, can suggest that the higher grades students achieved, the more demanding and critical they become not only with the used resources but with their learning too. In fact, the same kind of negative correlation also appears in relation to other reference materials consultation and in the other courses as well. This becomes more prominent in Case A2, where the consultation of course contents, which includes the VISIR manuals, appears negatively correlated with student performance markers (i.e., grades and CR). This corroborates the assumption that the students who achieve better grades do not feel so much need of consulting additional materials. In general, in the scientific course (Case A2) students tend to seek more information about the items directly related to the course itself and in the complementary courses (Cases B) students tend to seek more complementary materials. 
Finally, a qualitative assessment (Cohen et al., 2007) of the two open questions from the students SQ was also performed using content analysis, identifying emergent factors from students answers to: Q21 - What did you most enjoy about using VISIR remote lab? and Q22 - What inconveniences did youfind when using VISIR remote lab?

In general respondents tend to avoid answering open questions, so when they choose to do so, it is because they feel the need to express their opinion and usually what they write can be most meaningful in terms of identifying characteristics that are commonly (but independently) expressed. Each student may identify one or more aspects that were relevant to him/her. In this study, there was a high level of students who chose to answer these open questions in all courses: relatively to the ones who had answered the SQ: 83\% answered Q21 and 74\% answered Q22.

The qualitative analysis was conducted (Glaser \& Strauss, 1967), identifying for each expressed student comment a category which accounted their opinion (besides different linguistic formulations). This analysis process was performed by two researchers and confirmed by a third party. Since each respondent may have expressed more than one category, each response is distributed in the number of categories necessary to show its content. Therefore, what counts is not the number of respondents, but opinions expressed. For instance, in Q21, there were recurrent answers addressing the same issue that was categorized as no fear of damaging (when students express their relief of being able to assemble the circuits without fear of damaging the equipment): "I found it interesting to be able to handle the circuits in VISIR without fear of something undesirable happen"; "Do not be afraid to damage the equipment". In Q22, there was also recurrent comments addressing specific issues such as, for instance, operating (when students refer to issues of defective operating procedures): "Sometimes the system was bugged all day, both for group and individual activity"; "The handling in the circuit assembly could be more practical." Or related with Problems in understanding/working (when students admit or suggest that it is his/ her problem): "It tookmealong time to figure outhowIshould handle it properly.", "Understand howitworks."

In Case A2, 9 students answered Q21 and 10 answered Q22 and those answers allowed the identification of five factors ( 2 positive factors which denote student satisfaction and 3 negative ones which denote dissatisfaction). Two students answered "nothing" and "nothing in particular" to Q21. Even though similar words, these answers can have completely different meanings: the first is an expression that the student did not like anything at all about VISIR; the second expressing there is nothing to highlight. Taking into account Case B1, 208 students answered Q21 and 179 answered Q22, allowing the identification of 4 positive factors (from the 240 positive remarks students made) and 8 negative ones (from the 200 negative remarks). In Case B2, 118 students answered Q21 and 124, Q22. Their comments allowed the identification of the same factors already mentioned in the other cases, totalizing 133 positive and 108 negative remarks. Their answers' distribution among the identified factors and its summary per engineering major degree may be observed in Table 11. 
These results highlight what the students considered the added values of having used VISIR. The most referred factor was its easy accessibility from anywhere/anytime (independently of their major degree or course): 170 students out of the 335 students who choose to state an answer to Q21 (51\%), impartially chose this factor. In fact, from the data storage in the Maxwell System database, the percentage of student accesses on weekends, school holidays and from 7 p.m. to 7 a.m., was confirmed high: 46.2\% (Case B1) and 57.2\% (Case B2). And since these numbers do not account for the accesses performed outside of campus during daytime, these percentages are probably higher. Second factors most referred (even though not exactly with the same importance for students regardless their major), were better/more complete understanding or quality of the equipment (both representing $21 \%$ of answers). No fear of damaging came in third (16\%). 
Table 11

Qualitative assessment on the open questions (identified positive and negative factors (in shadow)).

\begin{tabular}{|c|c|c|c|c|c|c|c|c|c|c|c|c|c|}
\hline \multirow{2}{*}{\multicolumn{2}{|c|}{ Faęto (positive / negative) }} & \multicolumn{3}{|c|}{ Case A2 } & \multicolumn{8}{|c|}{ Case B1 } & Case B2 \\
\hline & & 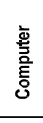 & 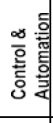 & 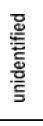 & 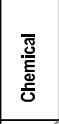 & $\sum_{i}^{\bar{z}}$ & 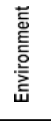 & 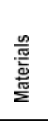 & 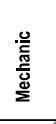 & $\begin{array}{l}\text { 辤 } \\
\text { 耪 } \\
\underline{\underline{\underline{g}}}\end{array}$ & 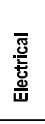 & 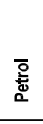 & ङ \\
\hline 巡 壳 & Better/ more complete understanding & & & & $7 / 7$ & $8 / 5$ & $1 / 0$ & $0 / 1$ & $11 / 3$ & 14 & & & $41 / 29$ \\
\hline & Problems in understanding & & & & $3 / 6$ & $15 / 4$ & $0 / 0$ & 0 & $9 / 1$ & & & & \\
\hline \multirow{6}{*}{ 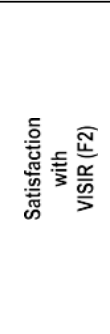 } & Access from anywhere/ anytime & 1 & 1 & & $18 / 5$ & $30 / 9$ & $2 / 1$ & $0 / 0$ & $21 / 4$ & & & & $129 / 39$ \\
\hline & No fear of damaging & & & 2 & $3 / 0$ & $11 / 3$ & $0 / 2$ & $1 / 0$ & $5 / 3$ & & & & \\
\hline & Quality of the equipment & & & & $1 / 6$ & $7 / 7$ & $0 / 2$ & $0 / 0$ & $6 / 4$ & & & & \\
\hline & Poor interface/ lack of info & 3 & 1 & 1 & 15 & 20 & $1 / 2$ & $1 / 0$ & $7 / 4$ & & & & \\
\hline & Errors not explained & 1 & & & $2 / 3$ & $0 / 0$ & $1 / 0$ & 0 & $0 / 1$ & & & & \\
\hline & Operating & 2 & 1 & 3 & $1 / 0$ & $7 / 1$ & $0 / 0$ & $0 / 1$ & $6 / 3$ & & & & \\
\hline \multirow{3}{*}{ 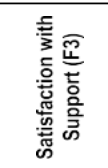 } & Lack of permanent assistance & & & & $2 / 2$ & $0 / 0$ & $0 / 0$ & 0 & $1 / 0$ & & & & \\
\hline & Insufficient preparation from classes & & & & $3 / 3$ & $3 / 0$ & $0 / 0$ & 0 & $4 / 0$ & & & & \\
\hline & Preference for traditional labs' features & & & & $0 / 0$ & $2 / 0$ & $0 / 0$ & 0 & $2 / 0$ & & & & \\
\hline $\begin{array}{l}\text { External } \\
\text { factors }\end{array}$ & Problems with Internet & & & & $0 / 4$ & $2 / 5$ & $1 / 0$ & 0 & $3 / 4$ & & & & \\
\hline \multicolumn{2}{|r|}{ Nothing positive to highlight } & 1 & & & $0 / 0$ & $0 / 0$ & $0 / 0$ & $0 / 0$ & $0 / 0$ & & & & \\
\hline \multicolumn{2}{|r|}{ Nothing negative to highlight } & 1 & 1 & & $3 / 1$ & $7 / 2$ & $0 /$ & $0 /$ & $8 / 2$ & 16 & & & $34 / 20$ \\
\hline
\end{tabular}

Regarding the challenge of choosing the things they did not like (Q22), again almost regardless of their major, students stated more often the poor interface/lack of info (102 out of 313 , that is, 33\%), problems in understanding (22\%) and operating was the third identified negative factor (17\%). Regarding the factor "lack of info", as PUC-Rio had substantially offered students materials and resources to work upon (Table 1), their low consultation levels (Table 8), must mean students were not properly enlightened of their existence.

\section{Discussion}

Cases A and B represent courses with different characteristics, planned for students with different backgrounds, profiles and interests. In fact, students from Case A are from majors related to Electricity/Electronics, so naturally interested and expert in these topics, while students from Case B are from majors in other areas, some probably not very motivated or expert in electricity. VISIR introduction, implementation and support in both Cases were also very different. The relevance of these differences will now be discussed.

The analysis of the results per course (described in the previous section) allowed a better 
understanding of each Case, char- acterizing the results of each strategy on implementing VISIR. The major decisions on each course design; implementation and student results were discussed. Now, in order to identify factors that might influence student results, the data from the three courses will be discussed together in order to identify some patterns.

In this vein, a global analysis was performed involving the 471 students results from all Cases. Due to their different char- acteristics in terms of factors related to the course, implementation, teachers or students, some other important correlations emerged. First, since students in each course were from different major degrees, it was important to understand if this variable had any influence. Performing a Chi-square independence test of each analysed variable with the student major degree, several significant dependences were found, namely with: VISIR grade, lab grade, exam grade, F1 (learning perception) and F2 (satisfaction with VISIR) (all $p<0.001$ except VISIR grade which reveals a $p=0.005$ ). However, the student logs pertask in VISIR appears to be independent from their major degree as already stated for the open questions in the student SQ.

Second, the implications of the different implementation characteristics on student results revealed several significant correla- tions, as shown in Table 12.

Through this analysis we can infer that for these implementations, even though their characteristics had no great influence on students VISIR usage, had significant influence on student VISIR performances, their perception of learning with the tool and their satisfaction with it. As seen above, students from Case A2 have a tendency to find the remote lab less useful than students from Cases

B. This result must be interpreted not only addressing their different level of expertise implementations (scientific or basic level of

Table 12

Correlations between implementation characteristics and student results.

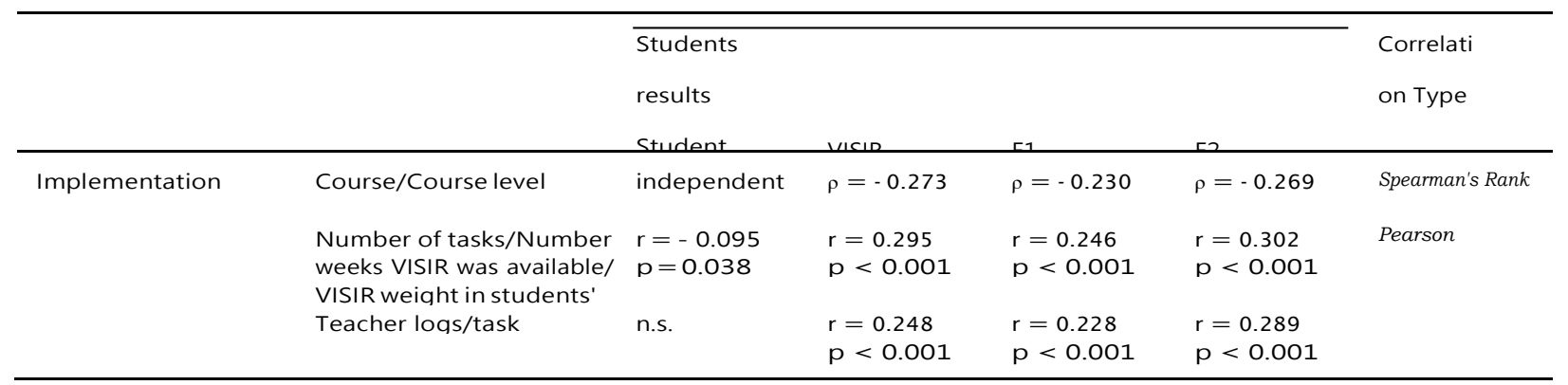

usage, respectively), but also (if not essentially) with respect to their different didactical issues: the fact that in Case A2 some characteristics were less interesting to student commitment (there was not a careful 
planned introduction activity; VISIR became an additional step with no additional grade and students interpreted this just as an extra effort and not as an opportunity since they had full access to hands-on lab).

As explained in last section, teacher involvement and VISIR usage was substantially different in the analysed courses and was found significantly correlated with student grades and their perception and satisfaction (F1 and F2). This corroborates that teachers' effort to motivate students and to give them support with their usage can play a determinant role not only for student satisfaction while using VISIR, but also as previous studies already stated, to overcome the natural difficulties of beginners and encourage students usage (Alves et al., 2011; Cunha et al., 2014; Garcia-Zubía, 2011; Marques et al., 2014). This result is interesting because it shows that this teachers' influence may not be directly on student usage, but rather on helping them understand the usefulness of the tool and being able to make the most of it.

Third, analysing the didactical implementation characteristics, the course level and the teacher usage of the system cannot be considered independent (Chi-square test of independence; $p<0.001$ ). More importantly, characteristics like the number of tasks, availability and weight on grade also highly influenced teacher VISIR usage $(r=0,919, p<0.001)$. This is understandable, since the more complex in number or in exigency the VISIR tasks are, the more demanding it will be for teachers to accomplish and support it, therefore dedicating more attention to it.

Fourth, student usage of VISIR appears correlated with the grade they achieve on VISIR tasks $(r=0.280, p$ $<0.001)$ and, on the other hand, student perception on learning (F1) is correlated with their satisfaction with VISIR (F2) $(r=0.652, p<0.001)$, meaning the more students felt the tool would aid their learning, the more satisfied they were with it, which may seem natural, but it also suggests coherence in their answers. However, neither student usage nor VISIR grade is correlated with F1 and F2. These results may prove important since it shows that student general happiness with VISIR was not dependent on the quantity or the quality of their efforts but as already pointed out in this discussion, it seems highly dependent on external factors such as course characteristics, teacher ability to promote their motivation or the extent to which this effort would count on their grade.

In this study, students more often mentioned negative factor regarding VISIR, regardless of the course or their major, was "poor interface/lack of info". In the majority of the previous works (Fidalgo et al., 2014; Marques et al., 2014), the most identified factor had been "errors not explained". In fact, VISIR interface comes mostly on analogical instruments while PUC-Rio Labs are equipped with modern digital instruments and have the support of technical staff from 7 a.m. to 7 p.m. Even though the call of attention to the "VISIR interface" had already been suggested by Ferreira, Lacerda, Schlichting, and Alves (2014) and Lima, Viegas, Alves, and Garcia- Peñalvo (2016), this study, due to the number of students involved, reinforces and suggests that VISIR could actually benefit from a renewal. In fact, VISIR is already at its 19th "birthday" (OpenLabs 
Electronics Laboratory, s.d.) and perhaps its interface (based on the real lab instruments) is no longer so appealing to these new generations. The mentioned positive factors "accessibility from anywhere/ anytime" and "no fear of damaging" even though common to the mentioned previous works, do not appear by the same rank order. Now it seems more important to be able to access the lab from anywhere/anytime (by far the most identified factor of all). In fact, a high percentage of VISIR accesses (more than 46\%) was registered in Maxwell system as done outside regular class time faculty campus. This student reference/preference is in accordance with Corter et al. (2011) and can also be supported by PUC-Rio location in Rio de Janeiro: not only it is a city with a lot of traffic, but the university itself is not served by a good public transport network. Moreover, about $50 \%$ of this private university students have scholarships (for fees, food and/or transports), because they are from poor areas away from the university. The accessibility factor is also in accordance with the characteristics of the new generation of students being more immersed (and dependent) on network and digital technologies (Viegas et al., 2017).

As in other works performed in different contexts and using different tools (Garcia-Zubía et al., 2017; Lima et al., 2016; Marques et al., 2014; Nickerson, Corter, Esche \& Chassapis, 2007), this study showed a positive influence of VISIR on students' learning achievements namely VISIR usage was found statistically correlated with their grade in the tasks involving VISIR (in both Cases), and also with their final lab grades (in Case B).

6. Conclusions

The teachers' reflection upon the results of the analysed courses allowed them a better understanding of the implications of some decisions, including how they had presented this tool to students and motivated them in their usage versus how students responded. Their suggestions of some improvements on course designs related to the future VISIR implementations are now shared:

- In the Electric Circuits course, VISIR was introduced in 3 out of 10 experiments, adding an extra step to the experimental procedure, without enlarging the accounted grade. Students felt it was just an extra load of work without any (immediate) return.

Considering these, the teacher team changed their strategy. Due to a course remodulation (it was split into 2 courses though the total number of credits remains the same), VISIR will be able to serve two purposes. The first course (EC I) does not have lab activities but VISIR will be used to teach Thévènin Equivalent Circuit since students will not be able to access the contents of the black box (VISIR offers this option). The second course (EC II) has lab classes and VISIR will be used for the experiments of first order 
circuits in place of the workbench activity. Thus, there will be no additional workload.

- In the General Electricity course, this improvement was already naturally performed since this course had lack of hands-on practice and VISIR's prior goal was exactly to overcome this problem. VISIR implementation allowed a gain of $50 \%$, considering

the number of available experiments (from 8 to 12) and an increase of time spent performing experiments accordingly to student rate. Furthermore, the experiments and topics covered with VISIR are different from the ones covered with the traditional la- boratory, so the teachers decided to maintain their strategy.

The prior concern of this study was to better comprehend the incorporation of a remote lab (VISIR) in two different courses (one for EE major students and another for non-EE majors) in a higher education institution (PUC-Rio) identifying the conditions that might have most effect on student results. More generally, our hypothesis was that some factors could influence student motivation to use VISIR as well as the quality of the work produced with it. Our research question addressed the possibility of identifying some of thosefactors which teachers should besensitive when implementing a remotelab in their courses: "Whichfactors should teacherstackle

to foster student learning and motivation when implementing VISIR in their didactic approach?"

From this research some statistically significant and meaningful correlations allowed us to identify some aspects that teachers should understand in order to make the best of using VISIR in their classes:

1. Students may have different levels of acceptance while using this tool (in terms of their learning perception and satisfaction), which can impact on their learning achievements. However, students' opinions about VISIR most and least values are not de- pendent on their major or course. The greatest identified advantage of introducing a remote lab in a course was its accessibility - access from anywhere/anytime, allowing students to study and perform their tasks at their own pace (and repeat it as many times as they need). On the other hand, students also helped to identify VISIR greatest faults, naming first its poor interface. This result may also help future decisions while upgrading VISIR interface, addressing students' wish for a more modernized appearance.

2. The course and in particular the "course level" (scientific or basic course) had no influence on student usage but had significant influence on student VISIR performances, their perception of learning with the tool and their satisfaction with it. In the cases analysed, students from the scientific level found it less useful than the ones in which this topic was complementary. However, since VISIR was performed under different circumstances, namely its introduction and when it was presented in the semester, 
these factors may also have influenced this result (as seen), so a larger study is necessary to corroborate this assumption.

3. The course design, mainly "VISIR's availability", "demanded work" and the correspondent "weight in students' grade" were also important influential factors on student results. Students' perception of their effort versus its benefits can strongly affect their commitment while considering the task to be more or less interesting (denoting an extrinsic motivation to learn). In fact, this may not have a direct consequence on student usage of the tool (namely if VISIR usage is mandatory in order to accomplish a task) but, in this study, results indicate a significant influence on students' performance, perception of learning and satisfaction with the tool.

4. Teacher involvement and motivation to use VISIR strongly affected student's own perception of this tool usefulness. In this study, teacher usage of VISIR was found highly significantly correlated with student grades, student learning perception and satisfaction with it (even though not with student usage itself). Also considered of high importance is the way teachers involve students from the start, namely how VISIR is introduced to students and the support teachers offer in the initial period when students are trying to overcome their natural initial difficulties. On the other hand, the more demanding the work with VISIR will be, the more teachers will respond to it, so teachers' effort and commitment can be stimulated by understanding the benefits it can bring to students.

5. Considering student results and their influence on one another, it was found that student usage of VISIR directly potentiates their performance in VISIR's tasks and lab. However, that usage is independent from students' perception or satisfaction with it. This strongly indicates that even when VISIR usage is extrinsically motivated (by being mandatory and its usefulness for students learning development not fully explained/understood), student accomplishments can still grow with their usage. In fact, students' satisfaction with VISIR is significantly correlated with their learning perception of it, but not with their grades. On the other hand, students with higher grades can also be more demanding and critical regarding the available resources (some negative correla- tions were found between student grades and student usage of remote materials) which supports the conclusion that these re- sources can be more helpful to students with some difficulties than for students with more developed knowledge.

\section{Declarations of interest}

None. 
Acknowledgements

The authors would like to acknowledge the support of the VISIR Special Interest Group (VISIR SIG) as well as the financial support provided by the European Commission through grant 561735-EPP-1-2015-1-PT-EPPKA2CBHE-JP.

The authors would also like to acknowledge the financial support provided by the Foundation for Science and TechnologyProject, FCT UID/EQU/04730/2013.

References

Alves, G., Fidalgo, A., Marques, M. A., Viegas, C., Felgueiras, M., Costa, R., et al. (2016). Spreading remote labs usage: A system - a community - a federation.

Proceedings of the 2 nd international conference of the Portuguese society for engineering education (CISPEE2016). Vila real, Portugal.

Alves, G., Marques, M., Viegas, C., Costa Lobo, M. C., Barral, R., Couto, R., et al. (2011). Using VISIR in a large undergraduate course: Preliminary assessment results.

Global engineering education conference (EDUCON).

Alves, G., Viegas, C., Lima, N., \& Gustavsson, I. (2016). Simultaneous usage of methods for the development of experimental competences. International Journal of Human Capital and Information Technology Professionals, 7(1), 54-73.

Bochicchio, M., \& Longo, A. (2009). Hands-on remote Labs: Collaborative web laboratories as a case study for IT engineering classes. IEEE Transactions on Learning Technologies, 2(4), 320-330.

Brinson, J. R. (2015). Learning outcomes achievements in non-traditional (virtual and remote) versus traditional (hands-on) laboratories: A review of the empirical research. Computers \& Education, 87, 218-237.

Claesson, L., \& Hakansson, L. (2012). Using an online remote laboratory for electrical experiments in upper secondary education. International Journal of Online Engineering (IJOE), 8(S2).

Cohen, L., Manion, L., \& Morrison, K. (2007). Research methods in education (6th ed.). London and New York: Routledge Falmer.

Collingridge, D. (2014). Validating a questionnaire. Methodspace. Sage Publishing. Retrieved September 2017. Available at: https://www.methodspace.com/validating- a-questionnaire/.

Corter, J. E., Esche, S. K., Chassapis, C., Ma, J., \& Nickerson, J. V. (2011). Process and learning outcomes from remotely-operated, simulated, and hands-on student laboratories. Computers \& Education, 
57(3), 2054-2067.

Cunha, E., Saraiva, E., Santos, C., Dinis, F., \& Lopes, J. (2014). Teacher mediation actions and students' productive engagement during the use of computer simulations in physical science classrooms. SLACTIONS 2013: Research conference on virtual worlds - learning with simulations. Procedia Technol. 13, 76-85.

Feisel, L., \& Rosa, A. (2005). The role of laboratory in undergraduate Engineering education. Journal of Engineering Education, 94, 121-130. Felder, R., \& Silverman, L. (1988). Learning and teaching styles in engineering education. Engineering Education, 78(7), 674-681.

Ferreira, G. S., Lacerda, J., Schlichting, L. C., \& Alves, G. R. (2014). Enriched scenarios for teaching and learning electronics. Bilbao, Spain: Technologies Applied to Electronics Teaching (TAEE).

Fidalgo, A., Alves, G., Marques, A., Viegas, C., Costa-Lobo, C., Hernadez-Jayo, U., ... Gustavsson, I. (2014). Adapting remote labs to learning Scenarios: Case studies using VISIR and RemotElectLab. IEEE Revista Iberoamericana de Tecnologias del Aprendizage, 9(1), 33-39.

Garcia-Zubía, J. (2011). Using VISIR experiments, subjects and students. International Journal Online Engineering (IJOE), 7(2), 11-14 (REV2011).

Garcia-Zubía, J., Cuadros, J.,S.,R., Hernandez-Jayo, U., Orduña, P., Guenaga, M., ... Gustavasson, I. (2017). Empirical analysis of the use of the VISIR remote lab in teaching analog electronics. IEEE Transactions on Education, 60(2), 149-156.

Glaser, B., \& Strauss, A. (1967). The discovery of grounded Theory: Studies for qualitative research. New York: Adline Publishing Co. Gomes, L., \& Bogosyan, S. (2009). Current trends in remote laboratories. IEEE Transactions on Industrial Electronics, 56(12), 4744-4756.

Gustavsson, I., Nilsson, K., Zackrisson, J., Garcia-Zubia, J., Hernandez-Jayo, U., \& Nafalski, A. (2009). On objectives of instructional laboratories, individual as- sessment, and use of collaborative remote laboratoires. IEEE Transactions on Learning Technologies, 2(4), 263-274.

Heradio, R., de la Torre, L., Galan, D., Cabrerizo, F., Herrera-Viedma, E., \& Dormido, S. (2016). Virtual and remote labs in education: A bibliometric analysis. Computers in Education, 98, 14-38.

Herrera, O. A., Alves, G. R., Fuller, D., \& Aldimate, R. G. (2006). Remote lab Experiments: Opening possibilities for distance learning in engineering fields. In D. Kumar,

\& J. Turner (Eds.). International federation for information processing, 210, education for the 21st century-impact of ICT and digital resources (pp. 321-325). Boston: Springer.

IAOE (2015). Winners of the GOLC online laboratory award. Retrieved 2016, from http://lists.onlinelists.org/pipermail/iaoe-members/2015-February/000120.html. 
Lima, N., Viegas, C., Alves, G., \& Garcia-Peñalvo, F. (2016). VISIR's usage as an educational resource: A review of the empirical research. TEEM'16 proceedings of the fourth international conference on technological ecosystems for enhancing multiculturarility. Salamanca, Spain.

Lynch, C. (2003). Institutional repositories: Essential infrastructure for scholaarship in the digital age. (2. ARL bimonthly report, producer, \& United States) retrieved May 2017, from CNI - coalition for networked information. Last accessed May 2017 https://www.cni.org/publications/cliffspubs/institutional-repositories-infrastructure-for-scholarship/.

Marques, M. A., Viegas, M. C., Costa-Lobo, M. C., Fidalgo, A. V., Alves, G. R., Rocha, J. S., et al. (2014). How remote labs impact on course Outcomes: Various practices using VISIR. IEEE Transactions on Education, 57(3), 151-159.

Nickerson, J., Corte, J., Esche, S., \& Chassapis, C. (2007). A model for evaluating the effectiveness of remote engineering laboratoires and simulations in education.

Computers and Education, 49(3), 708-725.

aboratory. (n.d.). (BTH). Retrieved 2018, from

http://openlabs.bth.se/electronics/index.php/en?page=AboutPage\#.

Pavani, A. M., Barbosa, W. S., Calliari, F.,P. D., Lima, V. A., \& Cardoso, G. P. (2017). Integration of an LMS, a IR and a remote lab. Proceedings of REV 2017-international ConferAence on remote engineering and virtual instrumentation, (pp. 427-442). New York.

Pozzo, M. I., Borgobello, A., \& Pierella, M. P. (2018). Uso de cuestionarios en investigaciones sobre universidad: Análisis de experiencias desde una perspectiva situada [using questionnaires in research on university: analysis of experiences with a situated perspective]. Revista Latinoamericana de Metodología de las Ciencias Sociales, 8(2) (ISSN 1853-7863, under publication).

Viegas, M. C., Alves, G., Marques, A., Lima, N., Felgueiras, C., Costa, R., ... Kreiter, C. (2017). The VISIR + Project - preliminary results of the training actions. (1.-1. M. Proceedings REV2017 -14 th international conference on remote engineering and virtual instrumentation, ed.) online engineering $\&$ internet of things. Lecture notes in networks and systems series: Vol 22, (pp. 467-482).

Wright, C., Lopes, V., Montgomerie, T., Reju, S., \& Schmoller, S. (2014). Selecting a learning mangement system: Advice from an academic perspective (EDUCAUSE) Retrieved February 05, 2015, from EDUCAUSEreview http://www.educause.edu/ero/article/selectinglearning-management-system-advice-academic- perspective. 